\title{
Cytogenetic Study of the Leopard, Panthera pardus (Carnivora, Felidae) by Conventional Staining, G- banding and High-resolution Staining Technique
}

\author{
Alongkoad Tanomtong ${ }^{1, *}$, Sumpars Khunsook ${ }^{1}$, \\ Puntivar Keawmad ${ }^{1}$ and Krit Pintong ${ }^{2}$ \\ ${ }^{1}$ Genetics Program, Department of Biology, Faculty of Science, Khon Kaen University, \\ Muang, Khon Kaen 40002, Thailand \\ ${ }^{2}$ Biology Program, Faculty of Science and Technology, Surindra Rajabhat University, Muang, \\ Surin 32000, Thailand
}

Received December 3, 2007; accepted April 5, 2008

\begin{abstract}
Summary This is a cytogenetic study of the leopard, Panthera pardus (Carnivora, Felidae). Blood samples were taken from 2 males and 1 female. After the standard whole blood lymphocyte culture in the presence of colchicine, the metaphase spreads were performed on microscopic slides and airdried. Conventional staining, G-banding and high-resolution staining technique were applied to stain the chromosomes. The results showed that $2 n$ (diploid) of leopard was 38 , and the fundamental number (NF) was 72 in the male and female. There are 6 autosome types: A type had 4 large submetacentric and 2 medium submetacentric chromosomes, B type had 4 large acrocentric and 4 medium acrocentric chromosomes, $\mathrm{C}$ type had 2 large metacentric and 2 medium metacentric chromosomes, D type had 8 small submetacentric chromosomes, E type had 6 small metacentric chromosomes and F type had 4 small telocentric chromosomes. A pair of the short arm of chromosome E1 (chromosome pairs 14) showed a clearly observable satellite chromosomes. The X chromosome was small submetacentric chromosome and the $\mathrm{Y}$ chromosome was the smallest submetacentric chromosome. From the G-banding and high-resolution staining technique, the number of bands and locations in the leopard was 163 and 191 respectively, and each chromosome pair could be clearly differentiated. We found that chromosomes A1, B3, B4, C1, C2, D1, D3, E1, E2, E3, F1, F2, X and Y chromosome patterns were according to the domestic cat (Felis catus) chromosomes. Chromosomes A2, A3, B1, B2, D2 and D4 are similar to those of the domestic cat. These results show the evolutionary relationship between the leopard and domestic cat. The karyotype formula for the male and female leopard is as follows: $2 n(38)=\mathrm{L}_{2}{ }^{\mathrm{m}}+\mathrm{L}_{4}{ }^{\mathrm{sm}}+\mathrm{L}_{4}{ }^{a}+\mathrm{M}_{2}{ }^{\mathrm{m}}+\mathrm{M}_{2}{ }^{\mathrm{sm}}+\mathrm{M}_{4}{ }^{\mathrm{a}}+\mathrm{S}_{6}{ }^{\mathrm{m}}+\mathrm{S}_{8}{ }^{\mathrm{sm}}+\mathrm{S}_{4}{ }^{\mathrm{t}}+$ sex chromosomes
\end{abstract}

Key words Karyotype, Leopard (Panthera pardus), Chromosome

All members of family Felidae were considered to form major population in Appendix I and II of The Convention on International Trade in Endangered Species of Wild Fauna and Flora (CITES) and on The International Union for Conservations of Nature and Natural Resources (IUCN) Red list of threatened, endangered and extinct species (Baillie et al. 2004). Thailand has many charismatic felid species in the world, including marbled cat (Pardofelis marmorata Martin, 1837), fishing cat (Prionailurus viverrinus Bennett, 1833), leopard cat (Prionailurus bengalensis Kerr, 1792), flatheaded cat (Prionailurus planiceps Vigors and Horsfield, 1827), jungle cat (Felis chaus Guldenstaedt, 1776), Asiatic golden cat (Catopuma temminckii Vigors and Horsfield, 1827), clouded leopard (Neofelis nebulosa Griffish, 1821), leopard (Panthera pardus Linnaeus, 1758) and tiger (Panthera tigris Linnaeus, 1758) (Lekagul and McNeely 1977, 1988, Par et al., 2003). Nine species of family Falidae in Thailand can be divided into 2 subfamily, Felinae and Pantheinae, based on mor-

*Corresponding author, e-mail: tanomtong@hotmail.com 


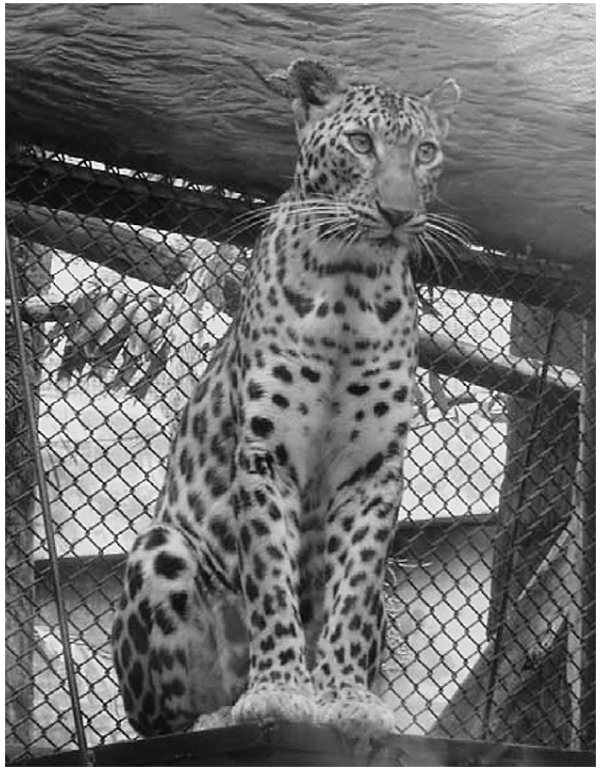

Fig. 1. The leopard, Panthera pardus (Carnivora, Felidae). phological classification (Wilson and Reeder 2006).

Habitat loss has occurred violently throughout Southeast Asia over the past 20 years and these felid species are vulnerable to population pressures and habitat fragmentation. Forest destruction has negatively affected on wild animals such as family Falidae. It reduces habitat for wild animals and causes population fragmentation due to the loss of genetic heterogeneity and thus they become vulnerable to environmental change and risk extinction.

The leopard is a big wild cat that is found in Africa, southern and eastern Asia as far north as Manchuria, south through Indochina to Malaya and Java. The common characteristics of the leopard are: Like many cats, leopards are sexually dimorphic, with male's considerable larger than females. The usual form is yellowish or tawny, with numerous black spots arranged in rosettes; the groups of spots are confined to the back and flanks, with single spots found on the head, legs, feet and under parts (Lekagul and McNeely 1977, 1988) (Fig. 1).

There are several reports on Cytogenetic studies of the family Felidae included Makino and Tateishi (1952), Thuline and Norby (1961), Ohno et al. (1962), Hsu et al. (1963), Matano (1963), Chu et al. (1964), Hus and Rearden (1965), Benirschke and Low (1966), Leyhausen and Tonkin (1968), Sutton (1968), Wurster and Benirschke (1967, 1968a, 1968b), Hard (1968), Wurster (1969), Milosevic et al. (1972), Wurster-Hill (1973), Wurster-Hill and Meritt (1974), Yang et al. (2000), Nie et al. (2002), and Keawmad et al. (2007). Our knowledge, cytogenetic study of the leopard, Panthera pardus (Carnivora, Felidae), can be a useful information for the conservation of family Felidae in Thailand.

\section{Materials and methods}

Blood samples of 2 males and 1 female clouded leopard were collected from Songkla Zoo, Thailand and then applied for cytogenetic studies by lymphocyte culture of whole blood samples. The culture cells were treated with a colchicine-hypotonic-fixation-air-drying technique followed by conventional staining, G-banding and high-resolution staining techniques with Giemsa's (Rooney 2001, Campiranon 2003). Twenty cells of each individual chromosome checks, length measurements, karyotyping and idiograming were accomplished by using light microscope as previously described (Chaiyasut 1989, Keawmad et al. 2007).

\section{Results}

Cytogenetic study of the leopard using lymphocyte revealed that the chromosome number is $2 n$ (diploid) $=38$ and the fundamental number (NF) is 72 in male and female. The autosomes of the leopard composed of 6 types: A type had 4 large submetacentric and 2 medium submetacentric chromosomes, B type had 4 large acrocentric and 4 medium acrocentric chromosomes, $\mathrm{C}$ type had 2 large metacentric and 2 medium metacentric chromosomes, D type had 8 small submetacentric 

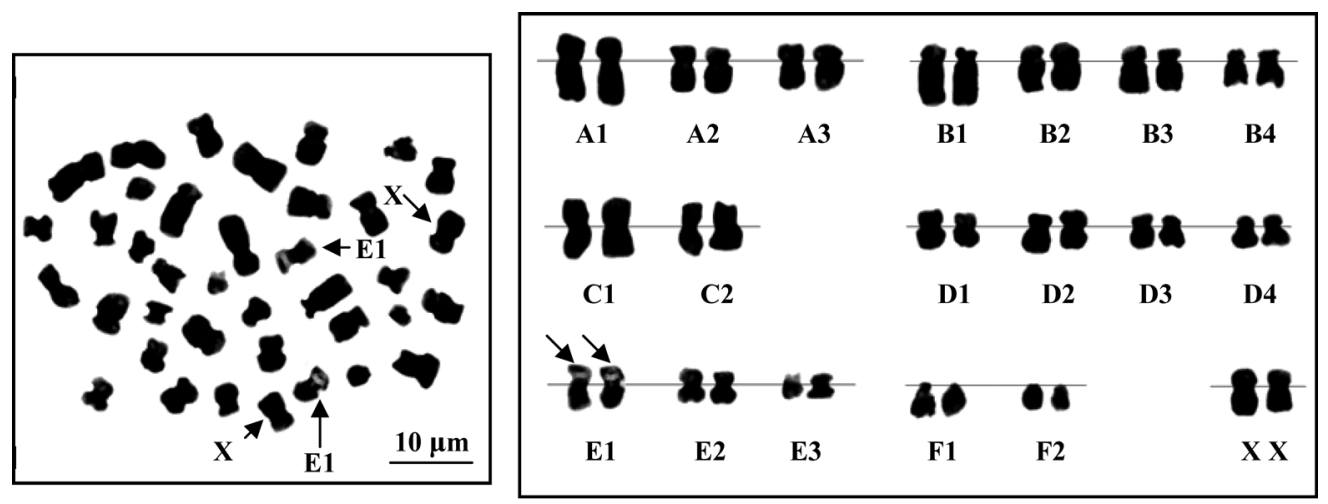

\section{A. Female of the leopard}
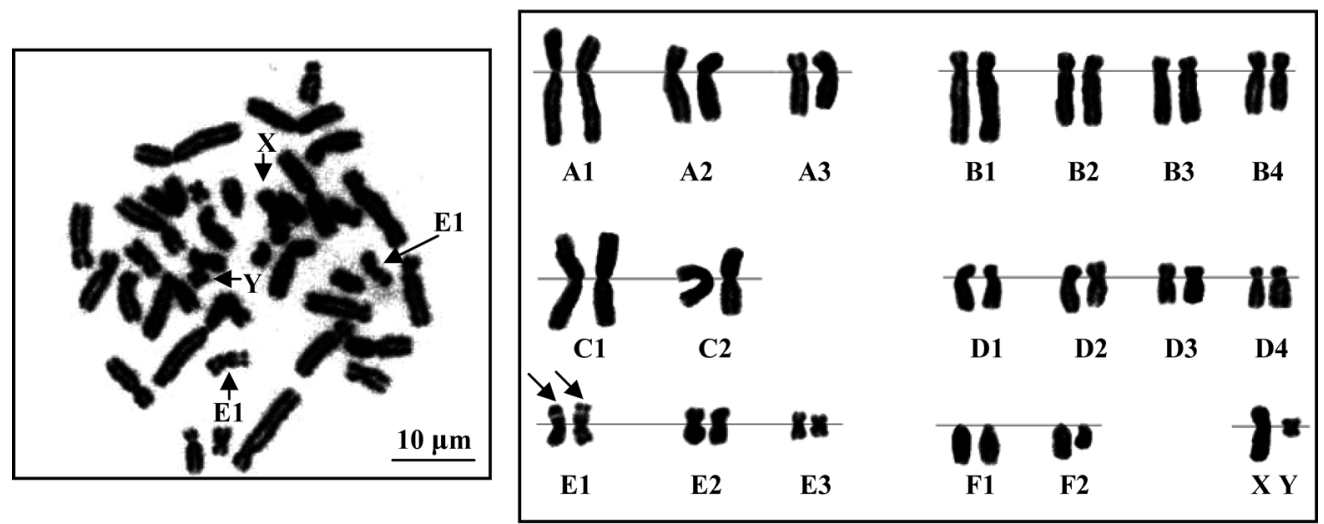

\section{B. Male of the leopard}

Fig. 2. Metaphase chromosome plates and karyotype of the female (A) and male (B) leopard (Panthera pardus Linnaeus, 1758) $2 n$ (diploid) $=38$ by conventional staining technique, showing satellite chromosomes with nucleolar organizer regions, NORs (arrows).

chromosomes, E type had 6 small metacentric chromosomes, and F type had 4 small telocentric chromosomes. A pair of the short arm of chromosome E1 (chromosome pairs 14) showed a clearly observable satellite chromosomes. The X-chromosome was small submetacentric chromosome and the Y-chromosome was smallest submetacentric chromosome (Figs. 2, 3, 4).

The important chromosome marker of the leopard is the asymmetrical karyotype, in which all 4 types of chromosomes are found (metacentric, submetacentric, acrocentric and telocentric chromosome). The results of the chromosomal checks on mitotic metaphase cells of the leopard are show in Tables 1 and 2. The largest and smallest chromosomes show large size difference (approximately 15 fold). The largest chromosome is submetacentric chromosome, while the second largest chromosome is metacentric chromosome and the $\mathrm{Y}$ chromosome is the smallest submetacentric chromosome (Figs. 2, 3, 4). Figure 5 shows the idiogram for the leopard from the G-banding technique, while Figure 6 shows the idiogram from the high-resolution staining technique with landmarks, bands and sub-bands. The G-banding revealed that the number of G-bands per haploid set, which includes autosomes, $\mathrm{X}$ and $\mathrm{Y}$ chromosomes, is 163 by the conventional technique and 191 by the high-resolution staining technique (Figs. 5, 6). 

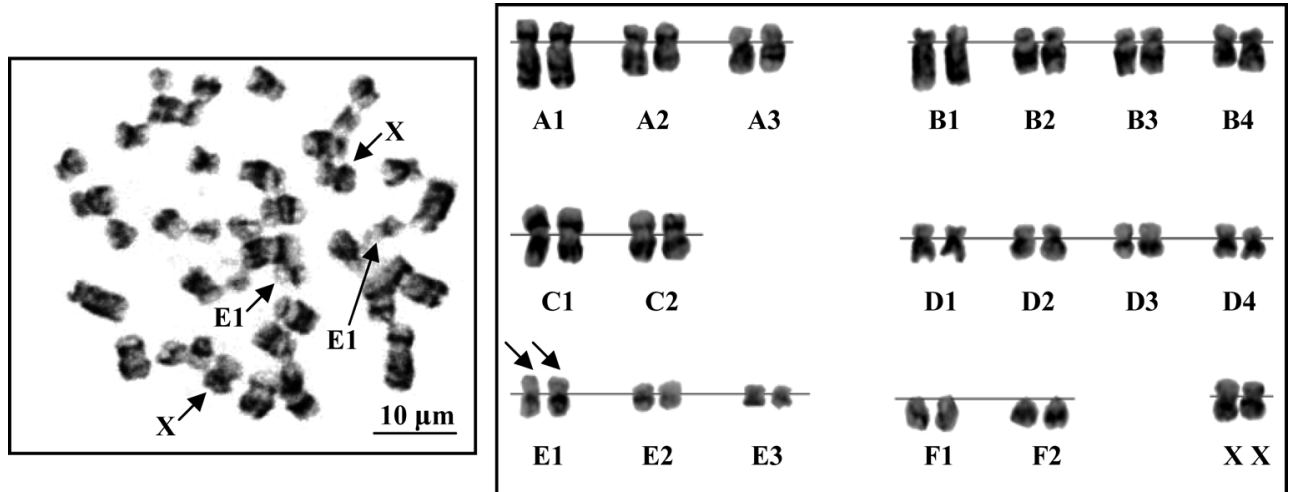

\section{B. Female of the leopard}

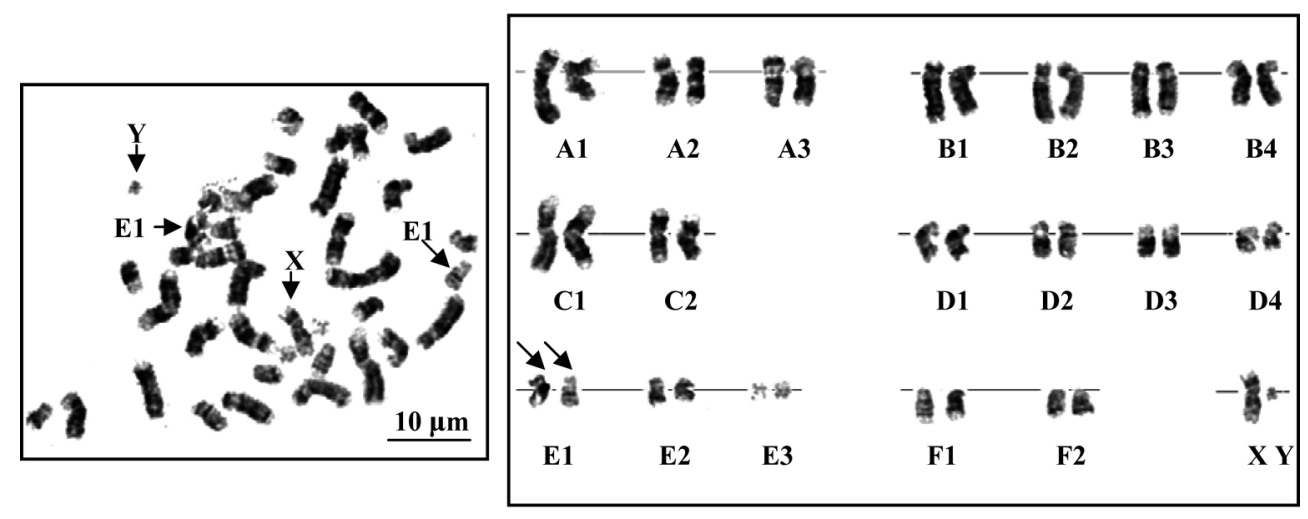

\section{B. Male of the leopard}

Fig. 3. Metaphase chromosome plates and karyotype of the female (A) and male (B) leopard (Panthera pardus Linnaeus, 1758) $2 n$ (diploid) $=38$ by G-banding technique, showing satellite chromosomes with nucleolar organizer regions, NORs (arrows).

Comparison of chromosome banding pattern between the leopard and the domestic cat (Felis catus) revealed that 14 chromosome pairs show the same pattern (pairs A1, B3, B4, C1, C2, D1, D3, E1, E2, E3, F1, F2, X and Y chromosome) and 6 chromosome pairs share similarities (pairs A2, A3, B1, B2, D2 and D4) (Fig. 7). This indicates that there is an evolutionary relationship between the leopard and the domestic cat. The karyotype formula for the leopard is as follows:

$2 n(38)=\mathrm{L}_{2}{ }^{\mathrm{m}}+\mathrm{L}_{4}{ }^{\mathrm{sm}}+\mathrm{L}_{4}{ }^{\mathrm{a}}+\mathrm{M}_{2}{ }^{\mathrm{m}}+\mathrm{M}_{2}{ }^{\mathrm{sm}}+\mathrm{M}_{4}{ }^{\mathrm{a}}+\mathrm{S}_{6}{ }^{\mathrm{m}}+\mathrm{S}_{8}{ }^{\mathrm{sm}}+\mathrm{S}_{4}{ }^{\mathrm{t}}+$ sex chromosomes.

\section{Discussion}

Cytogenetic study of the leopard using lymphocyte culture revealed that the chromosome number is $2 n=38$. This result agrees with the previous studies by Hsu et al. (1963) indicating that a member of the leopard family has $2 n=38$. This corresponds to $2 n$ for the member of the family Felidae according to reports in puma (Felis concolor), Canadian lynx (F. lynx), snow leopard (Uncia uncia), jaguarondi (F. yagouaroundi), cheetah (Acinonyx jabatus jabatus), serval (F. serval), fishing cat (F. viverrina), Asian leopard cat (Prionallurus bengalensis), bob cat (Lynx rufus), marbled cat (F. marmorata), European wild cat (F. silvestris), black footed cat (F. nigripes), tiger (P. tigris), do- 

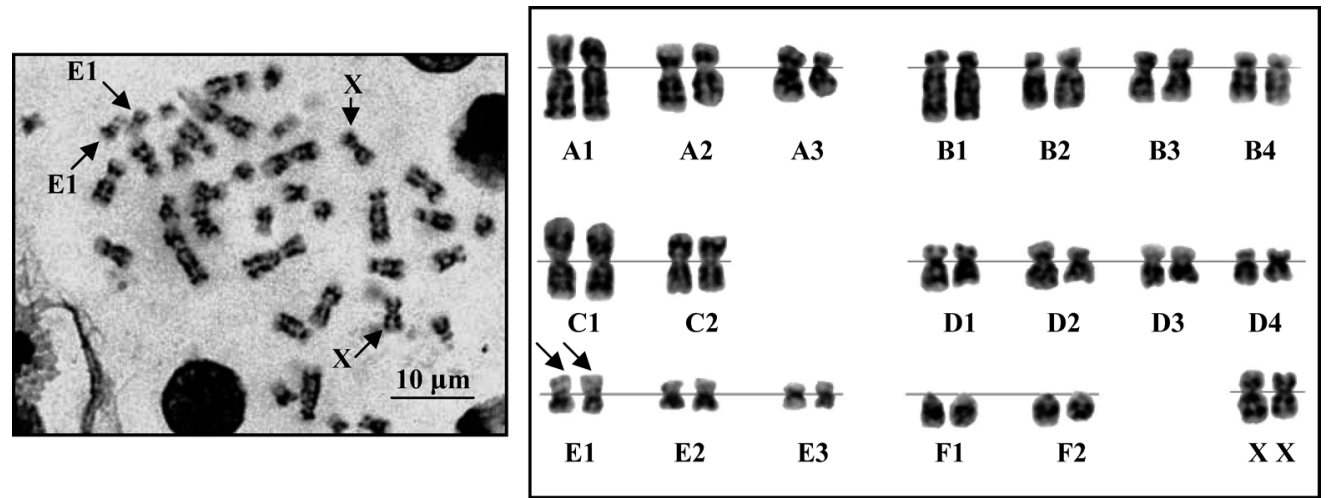

\section{A. Female of the leopard}
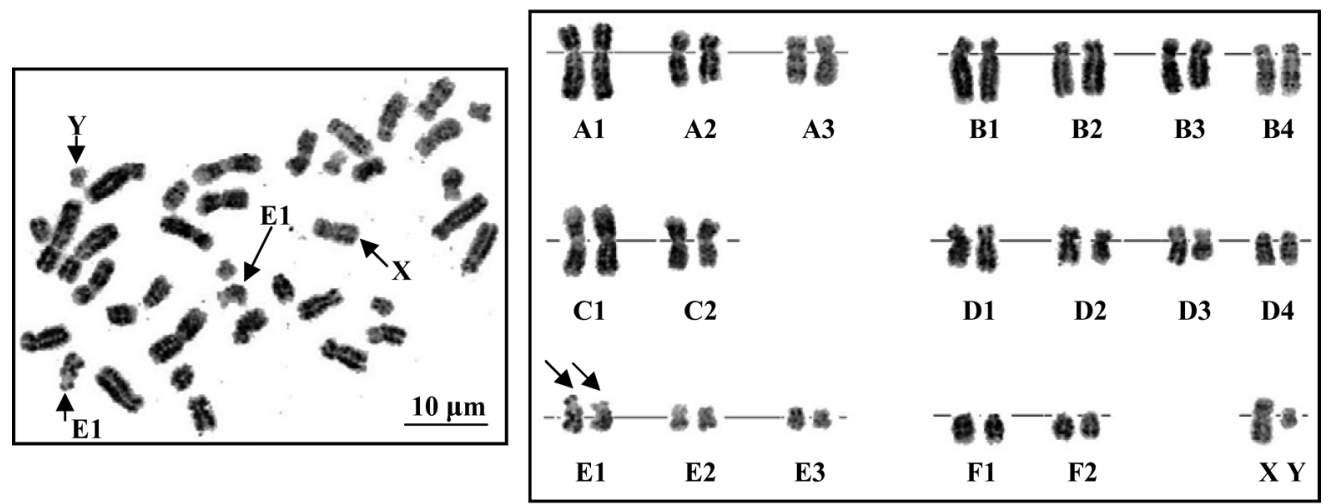

\section{B. Male of the leopard}

Fig. 4. Prometaphase chromosome plates and karyotype of the female (A) and male (B) leopard (Panthera pardus Linnaeus, 1758) $2 n$ (diploid) $=38$ by high-resolution staining technique, showing satellite chromosomes with nucleolar organizer regions, NORs (arrows).

mestic cat (F. catus) and ocelot (F. pardalis) (Makino and Tateishi 1952, Thuline and Norby 1961, Hsu 1962, Hsu et al. 1963, Hsu and Rearden 1965, Ohno et al. 1962, Matano 1963, Chu et al. 1964, Benirschke and Low 1966, Leyhausen and Tonkin 1968, Sutton 1968, Hard 1968, Wurster and Benirschke 1967, 1968a, 1968b, Wurster 1969, Milosevic et al. 1972, Wurster-Hill 1973, Wurster-Hill and Meritt 1974, Keawmad et al. 2007). However this number differs from the chromosome number of Geoffroy's (F. geoffroyi) and Marguay (F. wiedi) which is $2 n=36$ (Hsu 1962, Hsu et al. 1963a).

The autosomes of the leopard can be separated to 6 types: A type had 4 large submetacentric and 2 medium submetacentric chromosomes, B type had 4 large acrocentric and 4 medium acrocentric chromosomes, $\mathrm{C}$ type had 2 large metacentric and 2 medium metacentric chromosomes, D type had 8 small submetacentric chromosomes, E type had 6 small metacentric chromosomes and $\mathrm{F}$ type had 4 small telocentric chromosomes. The result agrees with the previous studies by Hsu et al. (1963) indicating that a member of the leopard family had 6 types of autosome: A type had 6 submetacentric chromosomes, B type had 8 acrocentric chromosomes, $\mathrm{C}$ type had 4 metacentric chromosomes, D type had 8 submetacentric chromosomes, E type had 6 metacentric chromosomes and 
Table 1. Mean of length short arm chromosome (Ls), length long arm chromosome (L1), length total arm chromosome (LT) (centimeter, cm), relative length (RL) centromeric index (CI) and standard deviation (SD) of RL, CI from metaphase chromosomes of 20 cells in female leopard (Panthera par$d u s$ Linnaeus, 1758) $2 n$ (diploid) $=38$.

\begin{tabular}{|c|c|c|c|c|c|c|c|}
\hline $\begin{array}{l}\text { Chromosome } \\
\text { pairs }\end{array}$ & Ls & $\mathrm{Ll}$ & LT & $\mathrm{CI} \pm \mathrm{SD}$ & $\mathrm{RL} \pm \mathrm{SD}$ & $\begin{array}{l}\text { Chromosome } \\
\text { size }\end{array}$ & $\begin{array}{c}\text { Chromosome } \\
\text { type }\end{array}$ \\
\hline A1 & 0.610 & 1.070 & 1.680 & $0.637 \pm 0.021$ & $0.049 \pm 0.001$ & $\mathrm{~L}$ & Submetacentric \\
\hline $\mathrm{A} 2$ & 0.410 & 0.780 & 1.190 & $0.655 \pm 0.022$ & $0.034 \pm 0.002$ & $\mathrm{~L}$ & Submetacentric \\
\hline A3 & 0.360 & 0.680 & 1.040 & $0.654 \pm 0.031$ & $0.030 \pm 0.002$ & M & Submetacentric \\
\hline B1 & 0.320 & 1.210 & 1.530 & $0.791 \pm 0.026$ & $0.044 \pm 0.003$ & $\mathrm{~L}$ & Acrocentric \\
\hline B2 & 0.290 & 0.870 & 1.160 & $0.750 \pm 0.024$ & $0.034 \pm 0.001$ & $\mathrm{~L}$ & Acrocentric \\
\hline B3 & 0.280 & 0.810 & 1.090 & $0.743 \pm 0.036$ & $0.032 \pm 0.004$ & M & Acrocentric \\
\hline B4 & 0.310 & 0.720 & 1.030 & $0.699 \pm 0.044$ & $0.030 \pm 0.002$ & M & Acrocentric \\
\hline $\mathrm{C} 1$ & 0.760 & 0.780 & 1.540 & $0.506 \pm 0.030$ & $0.045 \pm 0.004$ & $\mathrm{~L}$ & Metacentric \\
\hline $\mathrm{C} 2$ & 0.510 & 0.590 & 1.100 & $0.536 \pm 0.021$ & $0.032 \pm 0.002$ & M & Metacentric \\
\hline D1 & 0.290 & 0.540 & 0.830 & $0.651 \pm 0.036$ & $0.025 \pm 0.003$ & $\mathrm{~S}$ & Submetacentric \\
\hline D2 & 0.270 & 0.470 & 0.740 & $0.635 \pm 0.040$ & $0.021 \pm 0.002$ & $\mathrm{~S}$ & Submetacentric \\
\hline D3 & 0.250 & 0.470 & 0.720 & $0.653 \pm 0.028$ & $0.021 \pm 0.003$ & $\mathrm{~S}$ & Submetacentric \\
\hline D4 & 0.230 & 0.430 & 0.660 & $0.652 \pm 0.032$ & $0.019 \pm 0.003$ & $\mathrm{~S}$ & Submetacentric \\
\hline E1 & 0.360 & 0.410 & 0.770 & $0.532 \pm 0.030$ & $0.022 \pm 0.002$ & $\mathrm{~S}$ & Metacentric \\
\hline E2 & 0.280 & 0.320 & 0.600 & $0.533 \pm 0.034$ & $0.017 \pm 0.002$ & $\mathrm{~S}$ & Metacentric \\
\hline E3 & 0.240 & 0.320 & 0.560 & $0.571 \pm 0.028$ & $0.016 \pm 0.001$ & $\mathrm{~S}$ & Metacentric \\
\hline $\mathrm{F} 1$ & 0.000 & 0.620 & 0.620 & $1.000 \pm 0.000$ & $0.018 \pm 0.003$ & $\mathrm{~S}$ & Telocentric \\
\hline $\mathrm{F} 2$ & 0.000 & 0.540 & 0.540 & $1.000 \pm 0.000$ & $0.016 \pm 0.003$ & $\mathrm{~S}$ & Telocentric \\
\hline $\mathrm{X}$ & 0.250 & 0.390 & 0.640 & $0.609 \pm 0.014$ & $0.019 \pm 0.001$ & $\mathrm{~S}$ & Submetacentric \\
\hline
\end{tabular}

Remarks: $\mathrm{L}=$ large chromosome $(\mathrm{LT}>1.110), \mathrm{M}=$ medium chromosome $(\mathrm{LT}=0.840-1.110)$ and $\mathrm{S}=$ small chromosome $(\mathrm{LT}<0.840)$.

Table 2. Mean of length short arm chromosome (Ls), length long arm chromosome (L1), length total arm chromosome (LT) (centimeter, cm), relative length (RL) centromeric index (CI) and standard deviation (SD) of RL, CI from metaphase chromosomes of 20 cells in male leopard (Panthera pardus Linnaeus, 1758) $2 n$ (diploid) $=38$.

\begin{tabular}{cccccccc}
\hline \hline $\begin{array}{c}\text { Chromosome } \\
\text { pairs }\end{array}$ & Ls & L1 & LT & CI & RL & $\begin{array}{c}\text { Chromosome } \\
\text { size }\end{array}$ & $\begin{array}{c}\text { Chromosome } \\
\text { type }\end{array}$ \\
\hline A1 & 0.611 & 1.075 & 1.686 & $0.638 \pm 0.024$ & $0.047 \pm 0.004$ & $\mathrm{~L}$ & $\begin{array}{l}\text { Submetacentric } \\
\text { A2 }\end{array}$ \\
A3 & 0.405 & 0.764 & 1.169 & $0.654 \pm 0.020$ & $0.032 \pm 0.003$ & $\mathrm{~L}$ & $\begin{array}{l}\text { Submetacentric } \\
\text { B1 }\end{array}$ \\
B2 & 0.311 & 1.121 & 1.432 & $0.783 \pm 0.022$ & $0.040 \pm 0.002$ & $\mathrm{~L}$ & Acrocentric \\
B3 & 0.296 & 0.873 & 1.169 & $0.747 \pm 0.020$ & $0.032 \pm 0.002$ & $\mathrm{~L}$ & Acrocentric \\
B4 & 0.278 & 0.813 & 1.091 & $0.745 \pm 0.036$ & $0.030 \pm 0.006$ & $\mathrm{M}$ & Acrocentric \\
C1 & 0.301 & 0.708 & 1.009 & $0.702 \pm 0.044$ & $0.028 \pm 0.003$ & $\mathrm{M}$ & Acrocentric \\
C2 & 0.506 & 0.596 & 1.102 & $0.541 \pm 0.024$ & $0.030 \pm 0.004$ & $\mathrm{M}$ & Metacentric \\
D1 & 0.290 & 0.541 & 0.831 & $0.651 \pm 0.035$ & $0.024 \pm 0.004$ & $\mathrm{~S}$ & Submetacentric \\
D2 & 0.278 & 0.476 & 0.754 & $0.631 \pm 0.051$ & $0.021 \pm 0.002$ & $\mathrm{~S}$ & Submetacentric \\
D3 & 0.252 & 0.473 & 0.725 & $0.652 \pm 0.036$ & $0.020 \pm 0.002$ & $\mathrm{~S}$ & Submetacentric \\
D4 & 0.239 & 0.439 & 0.678 & $0.647 \pm 0.025$ & $0.019 \pm 0.001$ & $\mathrm{~S}$ & Submetacentric \\
E1 & 0.366 & 0.411 & 0.777 & $0.529 \pm 0.024$ & $0.021 \pm 0.002$ & $\mathrm{~S}$ & Metacentric \\
E2 & 0.280 & 0.316 & 0.596 & $0.530 \pm 0.028$ & $0.016 \pm 0.005$ & $\mathrm{~S}$ & Metacentric \\
E3 & 0.240 & 0.322 & 0.562 & $0.573 \pm 0.031$ & $0.016 \pm 0.004$ & $\mathrm{~S}$ & Metacentric \\
F1 & 0.000 & 0.613 & 0.613 & $1.000 \pm 0.000$ & $0.017 \pm 0.003$ & $\mathrm{~S}$ & Telocentric \\
F2 & 0.000 & 0.544 & 0.544 & $1.000 \pm 0.000$ & $0.015 \pm 0.003$ & $\mathrm{~S}$ & Telocentric \\
X & 0.254 & 0.395 & 0.649 & $0.609 \pm 0.012$ & $0.018 \pm 0.001$ & $\mathrm{~S}$ & Submetacentric \\
Y & 0.043 & 0.065 & 0.108 & $0.602 \pm 0.027$ & $0.003 \pm 0.001$ & $\mathrm{~S}$ & Submetacentric \\
\hline
\end{tabular}

Remarks: $\mathrm{L}=$ large chromosome $(\mathrm{LT}>1.115), \mathrm{M}=$ medium chromosome $(\mathrm{LT}=0.843-1.115)$ and $\mathrm{S}=$ small chromosome $(\mathrm{LT}<0.843)$. 

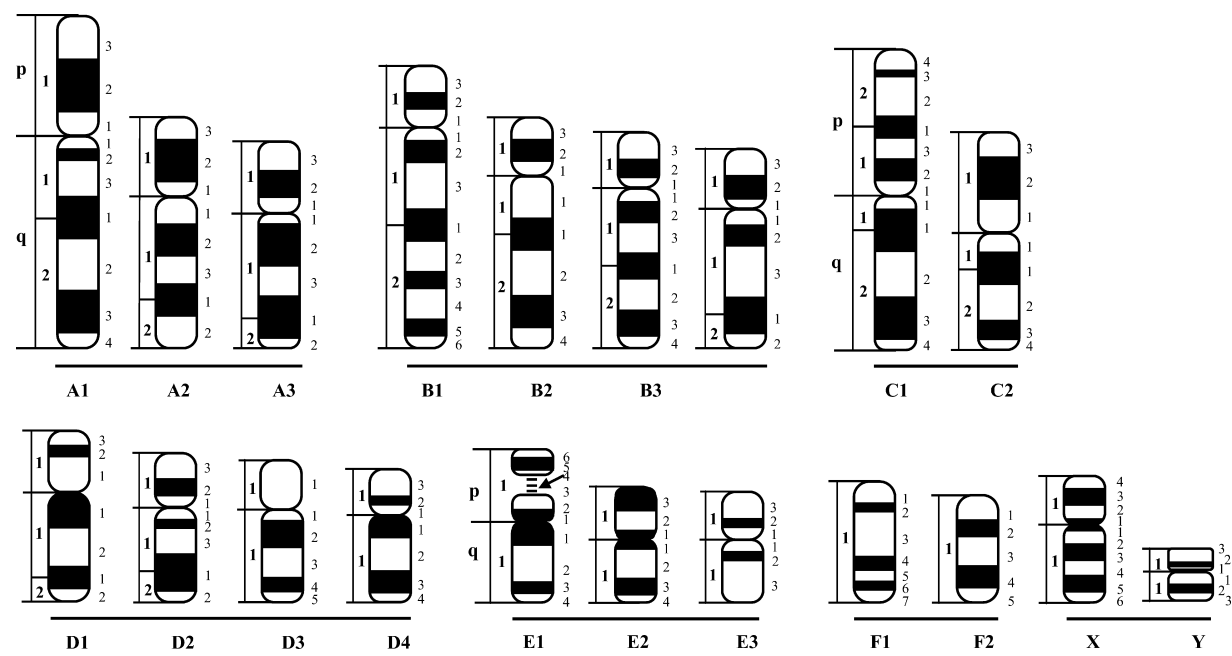

Fig. 5. Idiogram of the leopard (Panthera pardus Linnaeus, 1758) $2 n$ (diploid) $=38$ by G-banding technique. The arrow indicates nucleolar organizer region (NOR).
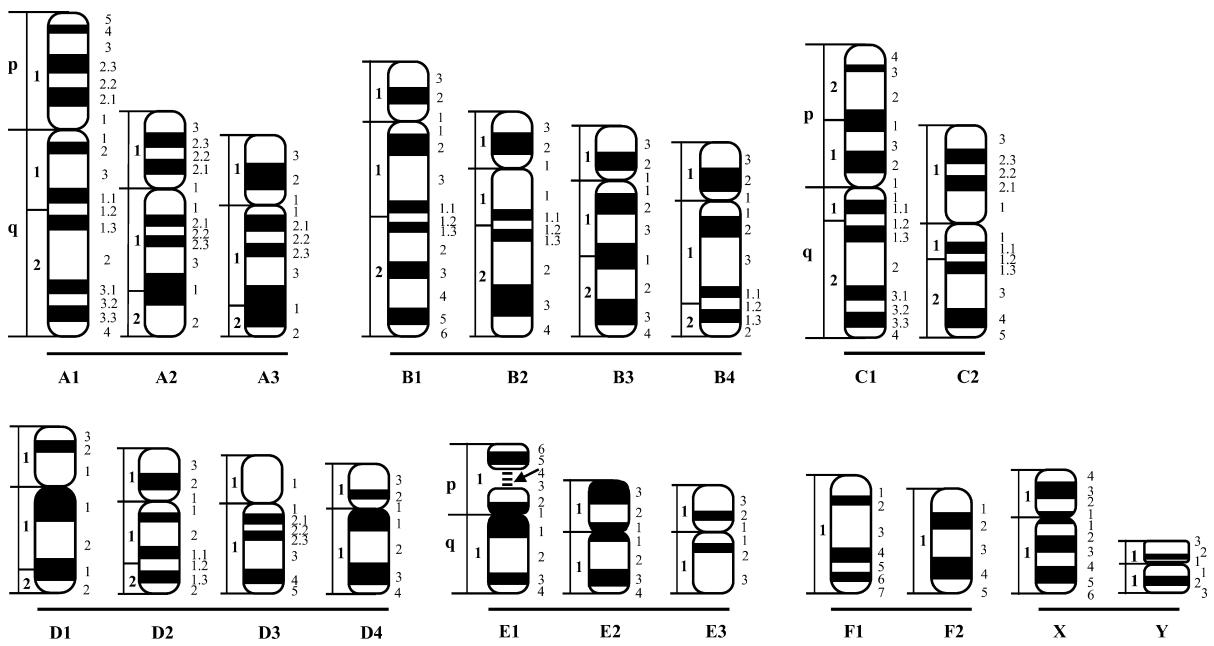

Fig. 6. Idiogram of the leopard (Panthera pardus Linnaeus, 1758) $2 n$ (diploid) $=38$ by high-resolution staining technique. The arrow indicates nucleolar organizer region (NOR).

F type had 4 telocentric chromosomes.

The NF of the leopard is 72 in male and female. For the sex-chromosomes, the $\mathrm{X}$ chromosome was small submetacentric chromosome and the Y chromosome was smallest submetacentric chromosome. This result agrees with the previous studies by Hsu et al. (1963). The comparison of the leopard $\mathrm{X}$ and $\mathrm{Y}$ chromosomes to those of the domestic cat indicated that the $\mathrm{X}$ chromosome was the medium submetacentric chromosome and the $\mathrm{Y}$ chromosome was the smallest submetacentric chromosome (Thuline and Norby 1961, Ohno et al. 1962, Matano 1963, Chu et al. 1964, Hsu and Rearden 1965). The comparison of the leopard X and Y chromosome to animals in family Felidae in Thailand namely, clouded leopard (Pardofelis nebulosa) found that X and Y chromosome were submetacentric and subtelocentric chromosomes in this species (O'Brien et al. 2006). 


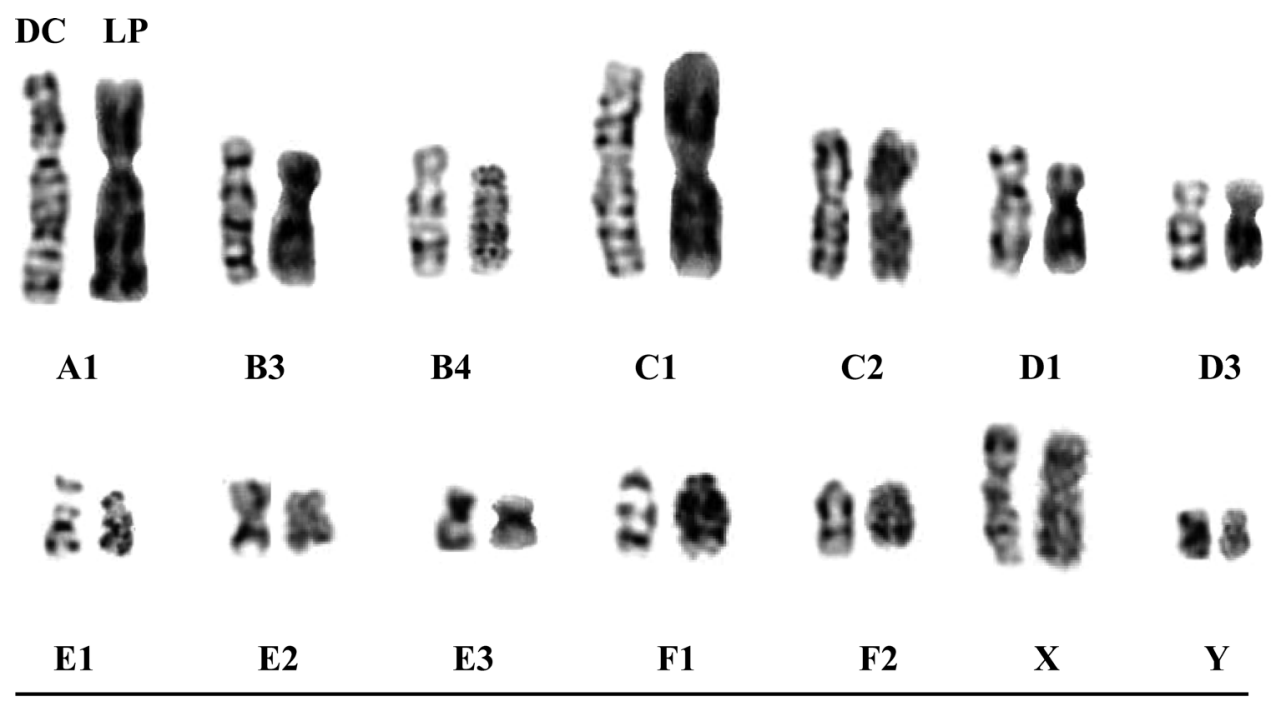

A

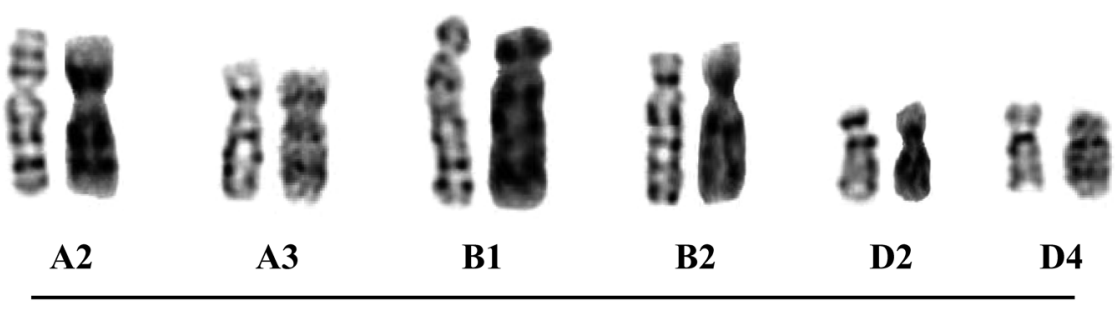

B

Fig. 7. A comparison of the chromosome of animal species in the family Felidae in Thailand, between domestic cat, Felis catus (DC, left) (Nie et al. 2002) and leopard, (Panthera pardus Linnaeus, 1758) (LP, right) in this study, showing the same (A), similar (B) and different (C) by G-banding patterns.

From this study, the leopard had the chromosome marker at the short arm of chromosomes E1 (chromosome pairs 14) that was a satellite chromosomes with nucleolar organizer regions (NORs). This result agrees with previous reports about the chromosomes E1 of animals in the family Felidae having a satellite chromosomes (Makino and Tateishi 1952, Thuline and Norby 1961, Hsu 1962, Hsu et al. 1963, Hsu and Rearden 1965, Ohno et al. 1962, Matano 1963, Chu et al. 1964, Benirschke and Low 1966, Leyhausen and Tonkin 1968, Sutton 1968, Hard 1968, Wurster and Benirschke 1967, 1968a, 1968b, Wurster 1969, Milosevic et al. 1972, Wurster-Hill 1973, WursterHill and Meritt 1974, Keawmad et al. 2007).

The G-banding by the conventional and high-resolution staining techniques revealed that the number of G-bands per haploid set, which includes autosomes, X and Y chromosomes, is 163 and 191, respectively. Comparing with the study in a domestic cat by Yang et al. (2000), there are 317 bands on 1 set of the metaphase haploid chromosomes. The present study showed a lower number of bands compared with previous studies because only clearly observable bands of the chromosomes were counted.

Comparison of chromosome banding patterns between the leopard and the domestic cat (Nie et al. 2002) revealed that thirteen chromosome pairs show the same pattern (pairs A1, B3, B4, C1, C2, 
D1, D3, E1, E2, E3, F1, F2, X and Y chromosome) and 6 pairs share similarities (pairs A2, A3, B1, $\mathrm{B} 2, \mathrm{D} 2$ and D4). This indicates that there is evolutionary close relationship between the leopard and the domestic cat. For further studies, more information about genetic differences is needed which may be accomplished by using molecular biology or molecular genetics.

\section{Acknowledgement}

The financial support from The Zoological Park Organization under the Royal Patronage of H.M. the King is gratefully acknowledged. We also thank Mr. Sopon Dumnui, Director of the organization, Dr. Sumat Kamolnaranath, Chief of the Educational Division and Director of Songkhla Zoo, for valuable help.

\section{References}

Baillie, J. E. M., Hilton-Taylor, C. and Stuart, S. N. 2004. 2004 IUCN red list of threatened species. A global species assessment. IUCN, Gland, Switzerland and Cambridge, UK. XXIV+, pp. 191.

Benirschke, K. and Low, R. J. 1966. Chromosome studies of four carnivores. Mammalian Chromosome Newsletter 21: $148-160$.

Campiranon, A. 2003. Cytogenetics. 2nd ed. Department of Genetics, Faculty of Science, Kasetsart University, Bangkok, Thailand.

Chaiyasut, K. 1989. Cytogenetics and cytotaxonomy of the family Zephyranthes. Department of Botany, Faculty of Science, Chulalongkorn University, Bangkok, Thailand.

Chu, E. H. Y., Thuline, H. C. and Norby, D. E. 1964. Triploid-diploid chimerism in a male tortoiseshell cat. Cytogenetics 3: $1-8$.

Hard, W. L. 1968. The karyotype of a male cheetah, Acinonyx jabatus jabatus. Mammalian Chromosome Newsletter 9: $16-25$.

Hsu, T. C. 1962. Two species of cats with 36 chromosomes. Mammalian Chromosome Newsletter 8: 4-10.

-, Arrighi, F. E. and Luquette, G. F. 1963. Karyological studies of nine species of Felidae. Am. Nat. 97: $225-232$.

— and Rearden, H. H. 1965. Further karyological studies on Felidae. Chromosoma 16: 365-371.

Keawmad, P., Tanomtong, A. and Khunsoon, S. 2007. A study on karyotype of the Asian leopard cat, Prionailurus bengalensis (Carnivora, Felidae) by Conventional staining, G-banding and high-resolution technique. Cytologia 72: $101-110$.

Lekagul, B. and McNeely, J. A. 1977. Mammals of Thailand. 1nded. Kurusapha Ladprao Press, Bangkok, Thailand.

— and - 1988. Mammals of Thailand. 2nded. Sahakarn Bhaet, Bangkok, Thailand.

Leyhausen, P. and Tonkin, B. A. 1968. Comment on the karyotypes of the leopard cat and fishing cat. Mammalian Chromosome Newsletter 9: 78-85.

Makino, S. and Tateishi, S. 1952. A comparison of the chromosomes of the lion, Chinese leopard cat and house cat. J. Morphol. 90: 93-99.

Matano, Y. 1963. A study of the chromosome in the cat. Japan Journal Gene. 38: 147-152.

Milosevic, M., Zivkovic, S. and Isakovic, I. 1972. Hromozomske karakteristike nekin carnivore Iz Srbij. Genetika (Beogard) 4: 1-9.

Nie, W., Wang, J., O’Brien, P. C. M., Fu, B. and Ying, T. 2002. The genome phylogeny of domestic cat, red panda and mustelid species revealed by comparative chromosome paining and G-banding. Chromo. Res. 10: 209-222.

O’Brien, S. J., Menninger, J. C. and Nash, W. G. 2006. Atlas of Mammalian Chromosome. Wiley-Liss, United States of America.

Ohno, S., Stenius, C., Weiler, C. P., Trujillo, J. M., Kaplan, W. D. and Kinosita, R. 1962. Early meiosis of male germ cells in fetal testis of Felis domestica. Exp. Cell Res. 27: 401-410.

Par, J., Komonpalin, K. and Wongkarasin, M. 2003. Mammals of Thailand. Sarakadee Press, Bangkok, Thailand.

Rooney, D. E. 2001. Human cytogenetics: constitutional analysis. Oxford University Press: Oxford, UK.

Sutton, D. A. 1968. Karyotype of a female bob cat, Lynx rufus californicus. Mammalian Chromosome Newsletter 9: 249-254.

Thuline, H. and Norby, D. E. 1961. Spontaneous occurrence of chromosome abnormality in cat. Science 134: 544-546.

Wilson, D. E. and Reeder, D. M. 2006. Mammal species of the world. 3 rd Edn. Johns Hophins University Press.

Wurster, D. H. and Benirschke, K. 1967. Chromosome number in thirty species of Canivora. Mammalian Chromosome Newsletter 8: 195-216. 
— and - 1968a. Comparative cytogenetic studies in the order Canivora. Chromosoma 24: 336-382.

— and - 1968b. Karyotype of four more species of cats. Mammalian Chromosome Newsletter 9: 236-245.

- 1969. Cytogenetic and phylogenetic studies in Carnivora. In: Comparative mammalian cytogenetics. Benirschke, K., ed., Springger-Verlag, N.Y.

Wurster-Hill, D. H. 1973. Chromosome of eight species from five families of Carnivora. Journal Mammalian 54: 763-782.

— and Meritt, D. A., Jr. 1974. The G-band chromosomes of the marbled cat, Felis marmorata. Mammalian Chromosome Newsletter 15: 14-19.

Yang, F., Graphodatsky, A. S., O’Brien, P. C. M., Colabella, A., Solanky, N., Squire, M., Sargan, D. R. and Ferguson-Smith, M. A. 2000. Reciprocal chromosome paining illuminates the history of genome evolution of the domestic cat, dog and human. Chromosome. Res. 8: 393-404. 